\title{
Implementing RFID in Libraries for Process Automation - Experiences from over Twenty Current Installations
}

\author{
by CHRISTIAN KERN, MARCEL NAUER
}

The slides of this paper can be found at: http://www.zhbluzern.ch/LIBER-

LAG/PP_LAG_04/Friday/M_Nauer/Praesentation_Bozen_03.pdf

\section{INTRODUCTION}

In recent years libraries enhanced their offer from books to materials like videos, music cassettes and most important CDs and DVDs. These items are quite expensive to buy and therefore have a high demand by the library users. Many libraries also try to offer some kind of social meeting point and incorporate a café or an attractive reading room. This all contributes to the positive new image of libraries. The extension of the collection and the increased demand lead to an increased amount of work and requires more staff. However, it is difficult to get additional budget for continuous costs. It is easier to do one-time investments in order to shift the repetitive work away from the desk and to automatic self service stations. Radio Frequency Identification (RFID) is an established technology (since 2001) to take over the repetitive tasks: check out, return of items, sorting and inventory control. RFID-Systems have a maximum effect if there is also a good room planning which supports their function and the frequency of their use (Kern, 2002, 2004; Wampfler, 2003).

In this paper two approaches for the allocation of functional units in a library are compared:

- the traditional central allocation of the functional units at the counter (used by the staff)

- $\quad$ the decentral allocation of functional units, used by the library visitor

After this theoretical view some practical recommendations for the library and the architectural planner are given.

These are derived from experiences of RFID installations in over 20 libraries (Bibliotheca RFID Library Systems AG).

\section{COMPARISON OF CENTRAL AND DECENTRAL ALLOCATION OF THE FUNCTIONAL UNITS}

Fig. 1 shows a model for the central allocation of functional units, fig. 2 the decentral allocation. It only takes the room, which can be accessed by the public into account. The sorting, tagging of items, and administration (actions which usually take place in a separate room) are not shown. Using this model in other libraries with different layout of course requires some adaptation. In both models all units are connected to the Library Management System (LMS).

Fig. 1 shows that almost all functions are centralized at the counter, which is the check out, return, extension of the lending period, payment of fees, registration of new visitors and finally the consultation. The central processing makes sense because many different processes are performed by one single person. In this case it is far more time efficient if the visitor comes to the counter.

Corresponding to this need the most frequent way of the visitor is the way to the counter. Some visitors might first look for new items to borrow on the shelves and do the return of media at the same time when they check out the new ones (in that case they will only go once to the counter). Or they consult the OPAC-terminal (Online Public Access Catalogue) first to find the required items and their location. After the removal of the item from the shelf and the check out process at the counter, it has to be identified - which is normally done by reading the barcode with a hand scanner. In most cases the security system, which is the EM (electro magnetic) strip, will be deactivated (these strips must be re-activated one by one when the item has been returned). The visitor now leaves the library.

One important observation is that there are waiting lines in front of the counters during peak hours. Longer and shorter actions are mixed, such as the registration of new visitors and the simple return of books. Many visitors who have to wait in the line have no patience to wait for the "slow" persons. 
Fig. 1: Central function and the most frequently used way of the visitor in the library

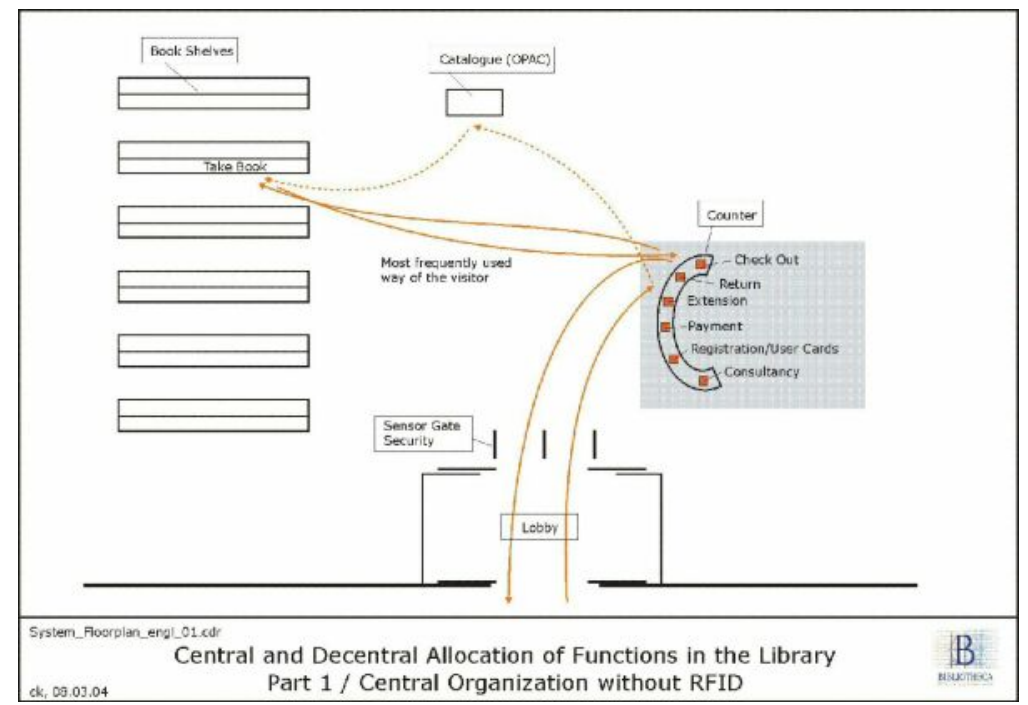

As all these important actions must be done there is only little time left for consultancy in peak hours. In fact, consultancy comes last at these occasions.

Fig. 2 shows the decentral allocation of the functional units. Only two functions remain at the counter, which is consultancy and registration of new visitors. All other functions like check out, return, payment, and renewal of the lending period are done by stations, which seem to be "spread" over the public room. Almost all stations have an integrated RFID reader device in order to identify the person and the item. The security function in the sensor gate is covered by the RFID system. When the items are returned in a separate RFID unit, the re-entering of their data into the database (status changed to "item in library") takes place together with the re-activation of the security function.

With the decentral allocation the most frequent ways of the visitors change. Some of the visitors do not even enter the library if they just want to return some items. They can do this in the lobby room at the entrance. This is also possible at non-opening hours. The counter can be much smaller now and is located in the background. The Self Check Out Station and the other units are in the foreground. The consultancy is not bound to the counter anymore: it can be done by the staff and even when the visitor walks around between the shelves. In the UK this type of consultancy was recently named as "floor walking".

Of course these two models are simplifying the true processes in a library. Here $100 \%$ of the check out processes is done at the stations. But in practical use there is the possibility to do some part of the check out and return at the counter like before - the difference is now that even here RFID is used to enhance the performance: items can be processed not only one by one but also in stacks like at the self check terminals. This leads to a significantly lower workload.

Fig. 2: Decentral functions with RFID technology and the most frequent way of the visitor

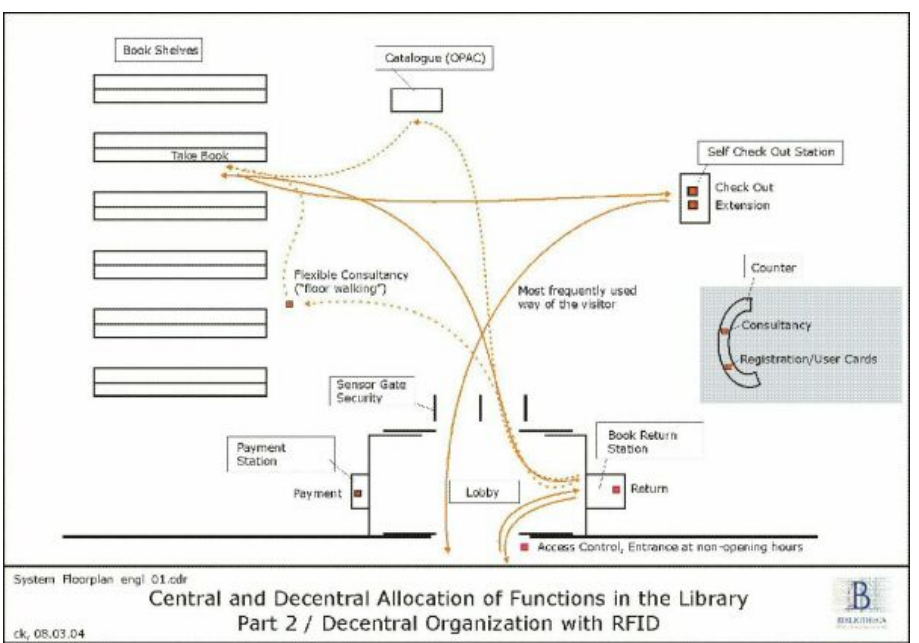


In a decentral library organization the stations are specialized for one single action which makes them very efficient. It is not suitable to combine too many actions in one unit again as this will again cause waiting lines at peak hours (many functions require much more time for the orientation of the user).

\section{RECOMMENDATIONS FOR THE ALLOCATION OF RFID UNITS IN LIBRARY ROOMS}

In this paragraph some practical recommendations for the integration of RFID stations are given (Tab. 1). Each station is mentioned in the text below with some additional remarks. The recommendations are based on the technical function of RFID devices (distribution of electromagnetic waves) and the practical experiences from more than 20 installations.

Tab. 1: Recommendations for the Integration of RFID Units in the Library

\begin{tabular}{|c|c|}
\hline RFID Unit & Recommendation \\
\hline $\begin{array}{l}\text { Allocation and design of the } \\
\text { Counter with integrated staff station }\end{array}$ & $\begin{array}{l}\text { - close to entrance / exit } \\
\text { - smaller counter, as less functions are needed } \\
\text { - no metal plates in the counter, avoid metal frames (possible influence on the } \\
\text { RFID performance) } \\
\text { - distance between keyboard and reader antenna of the staff station } \\
\text { - sufficient space for the placement of non-processed or processed items beside } \\
\text { the antenna }\end{array}$ \\
\hline $\begin{array}{l}\text { Allocation of the Self Check Out } \\
\text { Station }\end{array}$ & $\begin{array}{l}\text { - close to the counter in order to help visitors if they have problems in handling } \\
\text { - consider the privacy area around (content on the screen should not be seen } \\
\text { from waiting visitors) } \\
\text { - distance of at least } 2 \text { m between the Self Check Out Stations } \\
\text { - distance of at least } 4 \text { m to the sensor gate antenna } \\
\text { - possibility to place processed items on the side } \\
\text { - additional self check stations can be placed in special sections of the library } \\
\text { - children and disabled people require a lower station }\end{array}$ \\
\hline Allocation of the Sensor Gate & $\begin{array}{l}\text { - close to counter for direct access if an alarm is caused } \\
\text { - connections for video or turn style gates if requested } \\
\text { - distance to door of } 0,5 \mathrm{~m} \\
\text { - distance to shelves of min. } 4 \mathrm{~m} \\
\text { - distance to self check stations see above } \\
\text { - no metal in vicinity } \\
\text { - } 90 \text { cm width (or } 2 \text { x } 90 \mathrm{~cm} \text { ) } \\
\text { - consider plants to be placed at the sides if door is wider } \\
\text { - no floor heating system in the close area around the gate antennas (bolts } \\
\text { cannot be placed) } \\
\text { - some place for the RFID reader module must be given in } 6 \text { m distance from }\end{array}$ \\
\hline
\end{tabular}




\begin{tabular}{|c|c|}
\hline & $\begin{array}{l}\text { the antennas } \\
\text { - direct data cable to the counter for tracking of item numbers }\end{array}$ \\
\hline $\begin{array}{l}\text { Allocation of the Book Return } \\
\text { Station }\end{array}$ & $\begin{array}{l}\text { - built into wall or stand alone } \\
\text { - with or without sorting, room for extension should be considered } \\
\text { - accessible at non-opening hours, ideally in the library lobby room which can } \\
\text { be closed towards the main library room (similar to banks) } \\
\text { - accessible from the outside (this causes higher requirements for the housing } \\
\text { against vandalism and fire) } \\
\text { - accessible at a different location (away from library) is possible but requires } \\
\text { also protection against vandalism and fire and additional a logistic system to } \\
\text { pick up the items) }\end{array}$ \\
\hline Access Control & $\begin{array}{l}\text { - identification ideally with RFID user card } \\
\text { - antenna (Reader) at the side of the door } \\
\text { - no metal in } 25 \mathrm{~cm} \text { distance around the antenna }\end{array}$ \\
\hline Payment Station & $\begin{array}{l}\text { - in the lobby } \\
\text { - identification ideally with RFID user card }\end{array}$ \\
\hline Inventory Wand & $\begin{array}{l}\text { - correct position of labels in the book } \\
\text { - avoid metal shelves }\end{array}$ \\
\hline
\end{tabular}

Counter: should be located in the entrance area, to be able to control the security (sensor gates). It also should provide a line of sight to the self check out station to be able to offer help.

Self Check Out Station: it's definitely not recommended to make an own design of the furniture since there are a number of parameters to be taken into account, such as the handling of the materials and the distribution of the electromagnetic waves. The today offered furniture offers some variation in form, the possibility to locate it on a desk or a terminal and the variation of the color.

Security / Sensor Gates: for an optimal function it is important that the antennas are installed at a distance of $90 \mathrm{~cm}$ from each other. There can be 2 or 3 antennas in a row. The coverage of wider entrances $(>2 \times 0,90 \mathrm{~m})$ requires special antenna configurations. The space at the side of the antennas is covered by about $35 \mathrm{~cm}$, so that items, which are carried around, are also recognized. If there is more room to cover even plants can be used to block the way. In a case of emergency they are not blocking the way out.

Book Return Station: all of the book return stations installed by Bibliotheca were located in the lobby room. This offers the $24 \mathrm{~h}$ access and at the same time a control of the user. The user has to identify himself like in a lobby room of a bank when using a cash machine. This reduces the probability of damage and vandalism to the stations. A book return station which can be used from the outside of the building requires a far more rugged design.

Special attention should be given to the room behind the return station:

- If there is no sorting unit there should be at least sufficient room for bigger containers (with a self adjusting ground) and room for logistics.

- The number of items returned at a weekend is determining the size of the container.

During the automatic book return the control of the media for completeness or damages can only be done in a separate room, e.g. before they are put back onto the shelves.

For the planning of the book return station different requirements from local fire protection laws must be considered. 
Access Control: the door to a book return station should be equipped with an access control system. This can be done on the basis of magnetic user cards, but most favourably with RFID user cards. Barcode user cards are not suitable since they can easily be copied.

The reader antenna for RFID cards should be close to the door (arm length). Signs have to point out how the cards have to be used. There should be no metal around the antenna in about $25 \mathrm{~cm}$ distance.

Payment Station: this station can lead to a further decrease of routine work at the counter. It should - like the book return station - be accessible during $24 \mathrm{~h}$ and be located in the lobby room. The identification is done with the RFID card or the magnetic card. Various machines for a stand alone terminal or for integration into a wall are available (similar to parking payment machines). Also this unit needs to be linked to the LMS.

Inventory Control: for this function only two points have to be considered:

- the allocation of the labels in the book: to achieve a short distance between the label and the reader antenna and a maximum distance between metal shelves, the label should be placed in the middle of the book cover (consistently in front or back), close to the spine.

- The shelves should ideally not be made from metal. Although this cannot be changed in most of the existing libraries and the influence on the reading performance might be quite low, this can be taken into account when a new building is set up. The experiences in this field are still limited, since the development of the inventory wand was only recently finished.

\section{OUTLOOK}

In the above mentioned recommendations for the allocation of RFID units some potential applications were not yet discussed, such as the payment function at a coffee machine, at a copy machine or access to the internet. These units are relatively small components in the complete system; a self check out station in comparison offers the highest benefit. The experiences with these units might be presented at a later stage.

Looking at the decentral system it seems most important that there are significant changes regarding a lower workload at the counter. But these results are, apart from the technical function of the units, strongly dependent on the frequency of the stations and the allocation in the library. Experiences in the public library in Winterthur and the University Library in Leuven have shown that it is possible to guide more than $90 \%$ of the library visitors towards the RFID stations and the acceptance is very high (self check out and return in Winterthur, self check out in Leuven). The public library in Vienna reports of about $60 \%$ use of the self check out stations. We will report about these experiences also in a separate paper.

For the introduction of the RFID-Technology in libraries two main factors are relevant: the development of prices and the availability of standards. Prices came down more than 50\% from 1,20 EUR to 0,50 EUR (for a number of 100.000 labels, in 2003 to 2004). This was possible due to the increased application in other industry sectors (logistics, personnel identification). Accordingly, the investment costs for RFID become lower and seem affordable in many more libraries.

Looking at the above price development it is important to be able to participate in this development. Therefore standards are needed to be independent from the chip technology and its provider (being in a non-proprietary situation). The ISO standard 15693 provides this basis, which guarantees that other chips underlying the same standard can be used; ISO 15693 is incorporated in ISO 18000-3 (ISO 15693, 2001; ISO 18000, 2003). The standardization of the data format in the chips is not yet finished which would enable the compatibility between libraries of a country (the inter library loan amongst the branch libraries is already possible). To drive the standard for a data model various committees are working at the moment.

\section{REFERENCES}


collision and transmission protocol.

ISO/IEC FDIS 18000-3: 2003 (E) Information Technology AIDC techniques - RFID for item management - air interface. Part 3: Parameters for air interface communications at $13.56 \mathrm{MHz}$.

Kern, C.: "Radio-Frequenz-Identifikation zur Sicherung und Verbuchung von Medien in Bibliotheken". ABI-Technik 22(2002)3, 248-255.

Kern, C.: "Radio-Frequency-Identification for Security and Media Circulation in Libraries". Emerald Inside, May 2004

Wampfler, H.R.: "Mediensicherung in Bibliotheken". SAB-Info-CLP 2/2003, S. 21-24

\section{WEB SITES REFERRED TO IN THE TEXT}

Bibliotheca RFID Library Systems AG: http://www.bibliotheca-rfid.com/ 